\title{
How to manage the complicated hydatid cyst of the lung? Is any special surgical procedure more preferred?
}

\author{
F Caushi ${ }^{1 *}$, G Qirjako ${ }^{2}$, I Bani ${ }^{3}$, A Hatibi $^{4}$, I Skenduli', E Shima ${ }^{4}$, A Menzelxhiu ${ }^{1}$ \\ From 23rd World Congress of the World Society of Cardio-Thoracic Surgeons \\ Split, Croatia. 12-15 September 2013
}

\section{Background}

Echinococcosis is a biological, medical, economical and social concern of great importance for countries of Mediterranean area. The treatment of this disease has been successful including complicated cysts or not. Generally at the time of diagnosis simple cysts, or healthy ones which are intact, make $65 \%$ of the cysts, meanwhile the complicated cysts make $35 \%$ of them.

\section{Methods}

The medical data's for 181 patients of pulmonary hydatidosis treated in our clinic were retrospectively investigated. 145 of them $(80 \%)$ were treated surgically. 93 of them $(51,4 \%)$ were male and $88(48,6 \%)$ were females with a mean age 40 years (range 12-80 years). All the data were analyzed referring to Anova and $\chi^{2}$ test.

\section{Results}

$31.1 \%$ of cases were intact cysts and $68,9 \%$ were complicated cysts. $34,8 \%$ of intervened cases had complications, mainly air leakage ( $>7$ days) but there were not fatal cases. The cases with preoperative complicated cysts had postoperative complications 1.6 times more than for cases with simple cysts but there is no statistical significance. The mean number of the hospitalized days for complicated cysts was $(18.46 \pm 7.3)$ and the mean numbers of hospitalized days for intact cysts $(14.7+5.4)$ that has a statistical significance. The major part of patients with complicated cysts $(60 \%)$ had undergone an On Plat procedure, but there is no statistical significance between surgical method applied for preoperative complicated cysts concerning to postoperative complications.

\section{Conclusions}

Unlike other studies, in the major part of our cases the hydatid cysts were complicated. Although we didn't find any statistical significance connection between preoperative complicated cysts and postoperative complications, we concluded that complicated hydatid cysts prolong the hospitalized days of the patients, so it's better to treat them surgically at early stages. We also concluded that there is not a statistical preferred surgical technique for preoperative complicated cysts.

\section{Authors' details}

'Department of Thoracic Surgery, University Hospital of Lung Diseases, Tirana, Albania. ${ }^{2}$ Department of Statistics, University of Medicine, Tirana, Albania. ${ }^{3}$ Department of Pathology, Regional Hospital, Lushnje, Albania. ${ }^{4}$ Department of I.C.U., University Hospital of Lung Diseases, Tirana, Albania.

Published: 11 September 2013

\section{doi:10.1186/1749-8090-8-S1-P147}

Cite this article as: Caushi et al:: How to manage the complicated hydatid cyst of the lung? Is any special surgical procedure more preferred? Journal of Cardiothoracic Surgery 2013 8(Suppl 1):P147.

\footnotetext{
* Correspondence: fcaushi@yahoo.com

1 Department of Thoracic Surgery, University Hospital of Lung Diseases,

Tirana, Albania

Full list of author information is available at the end of the article
}

(c) 2013 Caushi et al; licensee BioMed Central Ltd. This is an Open Access article distributed under the terms of the Creative Commons 